\title{
Corticosteroid use in COVID-19 patients: a systematic review and meta-analysis on clinical outcomes
}

Judith van Paassen', Jeroen S. Vos ${ }^{1}$, Eva M. Hoekstra², Katinka M. I. Neumann², Pauline C. Boot ${ }^{2}$ and Sesmu M. Arbous ${ }^{1,3^{*}}$ (1)

\begin{abstract}
Background: In the current SARS-CoV-2 pandemic, there has been worldwide debate on the use of corticosteroids in COVID-19. In the recent RECOVERY trial, evaluating the effect of dexamethasone, a reduced 28-day mortality in patients requiring oxygen therapy or mechanical ventilation was shown. Their results have led to considering amendments in guidelines or actually already recommending corticosteroids in COVID-19. However, the effectiveness and safety of corticosteroids still remain uncertain, and reliable data to further shed light on the benefit and harm are needed.
\end{abstract}

Objectives: The aim of this systematic review and meta-analysis was to evaluate the effectiveness and safety of corticosteroids in COVID-19.

Methods: A systematic literature search of RCTS and observational studies on adult patients was performed across Medline/PubMed, Embase and Web of Science from December 1, 2019, until October 1, 2020, according to the PRISMA guidelines. Primary outcomes were short-term mortality and viral clearance (based on RT-PCR in respiratory specimens). Secondary outcomes were: need for mechanical ventilation, need for other oxygen therapy, length of hospital stay and secondary infections.

Results: Forty-four studies were included, covering 20.197 patients. In twenty-two studies, the effect of corticosteroid use on mortality was quantified. The overall pooled estimate (observational studies and RCTs) showed a significant reduced mortality in the corticosteroid group (OR $0.72(95 \% \mathrm{Cl} 0.57-0.87)$. Furthermore, viral clearance time ranged from 10 to 29 days in the corticosteroid group and from 8 to 24 days in the standard of care group. Fourteen studies reported a positive effect of corticosteroids on need for and duration of mechanical ventilation. A trend toward more infections and antibiotic use was present.

Conclusions: Our findings from both observational studies and RCTs confirm a beneficial effect of corticosteroids on short-term mortality and a reduction in need for mechanical ventilation. And although data in the studies were too sparse to draw any firm conclusions, there might be a signal of delayed viral clearance and an increase in secondary infections.

Keywords: COVID-19, SARS-CoV-2, Coronavirus, Corticosteroids, Mortality, Viral clearance, Mechanical ventilation

*Correspondence: marbous@lumc.nl

${ }^{1}$ Department of Intensive Care, Leiden University Medical Center, Albinusdreef 2, 2333 ZA Leiden, The Netherlands

Full list of author information is available at the end of the article

\section{Background}

Since the start of the outbreak, Coronavirus disease 2019 (COVID-19), caused by the novel coronavirus SARS-CoV-2, has spread globally from Wuhan, China. original author(s) and the source, provide a link to the Creative Commons licence, and indicate if changes were made. The images or other third party material in this article are included in the article's Creative Commons licence, unless indicated otherwise in a credit line to the material. If material is not included in the article's Creative Commons licence and your intended use is not permitted by statutory regulation or exceeds the permitted use, you will need to obtain permission directly from the copyright holder. To view a copy of this licence, visit http://creativecommons.org/licenses/by/4.0/. The Creative Commons Public Domain Dedication waiver (http://creativeco mmons.org/publicdomain/zero/1.0/) applies to the data made available in this article, unless otherwise stated in a credit line to the data. 
A total of 40,559,736 cases have been reported, and $1,121,499$ people have died as of October 19. [1] Many countries have been affected, causing immense stress on healthcare systems worldwide. This is the third epidemic caused by a coronavirus, after severe acute respiratory syndrome (SARS) in 2002 and Middle East respiratory syndrome (MERS) in 2012 [2, 3]. The clinical presentation ranges from asymptomatic or mild disease to severe pneumonia in which the most severe cases deteriorate with acute respiratory distress syndrome (ARDS) requiring prolonged mechanical ventilation, or even extracorporeal membrane oxygenation (ECMO) $[4,5]$. Approximately $16-35 \%$ develop severe pneumonia, $2-17 \%$ need mechanical ventilation, of whom up to $15 \%$ need ECMO therapy, [6-8] and the case fatality rate is $1.4-15 \%[5,9,10]$. In the pathophysiology of severe COVID-19, the host immune response plays a key role and it has become evident that COVID19 pneumonia is associated with both hyper inflammation and immunoparalysis [11]. A clinical presentation of massive vascular inflammation, disseminated coagulation, shock and ARDS is frequently triggered [9-11].

Though many therapies aiming at mitigation of the inflammatory response are being evaluated, strong evidence of benefit is lacking. Corticosteroids might have beneficial effects in overcoming both hyperinflammation and ARDS [4, 15-17]. Furthermore, they could serve as an easily accessible and affordable treatment option. On the other hand, there are known adverse effects of corticosteroid use, such as delayed viral clearance, opportunistic infections and suppression of the hypothalamic-pituitary-adrenal axis [2, 18, 19]. Earlier studies done in MERS-CoV and SARS-CoV showed delayed viral clearance, opportunistic infections and hyperglycemia [20-22]. Therefore, a high number of observational studies and randomized controlled trials (RCT) on corticosteroids for COVID-19 have been initiated and reported, and the signal is a beneficial effect. The RECOVERY trial was the first to report that the use of dexamethasone as opposed to usual care reduced 28-day mortality in patients requiring oxygen therapy or mechanical ventilation [23]. And a prospective meta-analysis of seven randomized clinical trials showed that administration of corticosteroids was associated with lower 28-day all-cause mortality [24]. And while initially the World Health Organization (WHO) recommended against corticosteroid treatment, as of September 2, 2020, the WHO recommends systemic corticosteroids rather than no systemic corticosteroids for the treatment of patients with severe and critical COVID-19 [15, 25]. Also, the Surviving Sepsis Guideline on management of COVID-19 recommends administration of steroids in patients with severe
COVID-19 on mechanical ventilation with ARDS and in patients with COVID-19 and refractory shock [26].

However, the effectiveness and safety of corticosteroids still remain uncertain, because of scarcity of RCTs and inconclusive observational studies, and reliable data to further shed light on the benefit and harm are needed. Therefore, the aim of this systematic review and meta-analysis of observational studies and RCTs was to evaluate the effectiveness and safety of corticosteroids in COVID-19.

\section{Methods}

\section{Data sources and search strategy}

A systematic review according to the PRISMA guidelines was conducted [27]. The meta-analysis was retrospectively registered under number 38752 at ISRCTN.org. A comprehensive systematic search was conducted for published studies in Medline/PubMed, Embase and Web of Science from December 1, 2019, to October 1, 2020. The search strategy consisted of the components "COVID19," "intensive care" and "corticosteroids" (Additional file 1).

\section{Eligibility}

RCTs and observational cohort studies assessing the effect of corticosteroids in COVID-19 were eligible if they met the following inclusion criteria: adult patients (age $\geq 18$ years), COVID-19 patients diagnosed by reverse transcriptase polymerase chain reaction (RTPCR), reporting on outcome measures in relation to corticosteroid treatment, corticosteroids not restricted with respect to type, dose and duration. Studies concerning pregnant women or children, reviews, case series including less than 15 patients and articles that were not available in English were excluded [28].

\section{Definition of primary and secondary outcomes}

The primary outcomes were short-term mortality (i.e., short-term mortality as defined in the study, including 28-day, 30-day and hospital mortality) and viral clearance (i.e., as defined by the study, based on RT-PCR in respiratory specimens). Secondary outcomes were: mechanical ventilation (i.e., as defined by the study: need for invasive mechanical ventilation, duration of mechanical ventilation, ventilator-free days or other oxygen therapy), length of hospital stay (LOS-hospital) and secondary infections. For exact used definitions see Additional file 2.

\section{Study selection}

Suitable studies were selected in two stages. First, six independent reviewers screened all selected titles and abstracts (JvP, JV, EH, KN, PB, SA). If there was consensus that a study was unsuitable for inclusion, it was 
excluded. Next, the full-text articles were screened independently by two authors and included if both authors agreed. If needed, the article was discussed with the third reviewer until consensus was reached.

\section{Data extraction and quality analysis}

After selection, data were extracted by one and checked by a second investigator (JvP, JV, EH, KN, PB). For each study, the author, journal, country, city and hospital in which the study was conducted, date of start of inclusion, study population, study groups, type, dose, route of administration of corticosteroids, median time before corticosteroid initiation, duration of administration, primary and secondary outcomes and adverse events at any time point after admission were extracted in a standardized data extraction form (Additional file 2).

For each individual study, the quality was assessed. For RCTs, the risk of bias was assessed on six domains (random sequence generation, concealment of allocation, blinding, selective outcome reporting, incomplete outcome data and other) $[29,30]$. The Newcastle Ottawa Scale was used for validity assessment of observational studies $[31,32]$. The NOS score ranges from 0 (low quality) to 9 (high quality) points.

\section{Data analysis and reporting}

For the effect of corticosteroids on mortality, a pooled estimate was calculated and graphically summarized in a forest plot. Data from observational studies were analyzed separately from the RCTs, and both the separate results and the overall combined outcomes were calculated and summarized in the plot. When available, the adjusted odds ratio (OR) or relative risk (RR) from the cohort studies were used for pooling to reduce confounding. Since the endpoint (mortality) occurred relative infrequently, the OR will be close to the RR and therefore we decided to pool both RR and OR estimates of the individual studies [33]. Furthermore, a pooled estimate was calculated and graphically summarized in a forest plot for need for mechanical ventilation.

To allow studies to have a different underlying effect, a random effects model was used. $\mathrm{I}^{2}$ statistics was used to quantify heterogeneity. Furthermore, for the pooled estimate of effect on mortality, tau ${ }^{2}$ was used to assess the variance of the true effects. The GRADE approach was used to assess the quality of the evidence for the effect of corticosteroids on mortality. STATA 16.0 was used to perform data analysis.

\section{Results}

\section{Study selection}

Our search yielded 1640 unique studies. After qualification of title and abstract, 101 studies were selected for full review. Based on exclusion criteria, 57 additional studies were excluded (references in Additional file 3). The remainder of 44 studies, comprising 20.197 patients, was included in this systematic review and meta-analysis. (Fig. 1).

\section{Study characteristics (Table 1 and Additional file 4)}

Thirty-one of the 44 studies originated in China, 11 in Europe, five in North America, two in South America and one study were multi-continental. The inclusion period of patients ranged from late December 2019 until August 20, 2020. The majority of studies were retrospective observational studies (37/44), five were RCTs [23, 34-37], and there were two studies with historical controls $[38,40]$. The study population varied from hospitalized patients (28/44) to patients admitted to the Intensive Care Unit (ICU) (15/44), and one study included discharged patients for viral clearance assessment. The median age of patients ranged from 34 to 75 years.

For the observational studies, the median NOS score was 5 (2-8) points (Additional file 5). For the RCT, the risk of bias table is depicted in Fig. 2.

\section{Corticosteroid regimen (Table 1 and Additional file 6)}

In the 44 studies, very diverse corticosteroid strategies were used. If reported $(n=35)$, methylprednisolone was the most frequently prescribed $(n=28)[35,36,38-65]$. Prednisone $(n=5)$ and dexamethasone $(n=5)$ and hydrocortisone $(n=4)$ were also used, some in studies that allowed multiple corticosteroid regimens $(n=9)$.

The indication to start corticosteroids was described in 12 studies (Additional file 6): In three studies, corticosteroids were started at diagnosis/hospital admission. [38, $41,56]$ In five studies, ICU admission or respiratory deterioration were the indications to start, either randomized according to study protocol $[23,34,35,37]$ or not randomized [38, 48, 49, 60, 64].

In 29 studies, the dose of corticosteroids was reported: In 16 studies, an equivalent dose of $>1 \mathrm{mg} / \mathrm{kg}$ prednisolone was used [37-39, 41, 43, 44, 48-51, 53, 54, 56-58, 64] and in 11 studies a lower equivalent dose than $1 \mathrm{mg} / \mathrm{kg}$ prednisolone [23, 34-36, 40, 42, 47, 52, 62, 63, 65]. In two studies, a low- and high-dose group were present $[45,46]$. The duration of therapy varied within a range of 5-10 days, in observational studies frequently dependent on clinical condition of patients. 


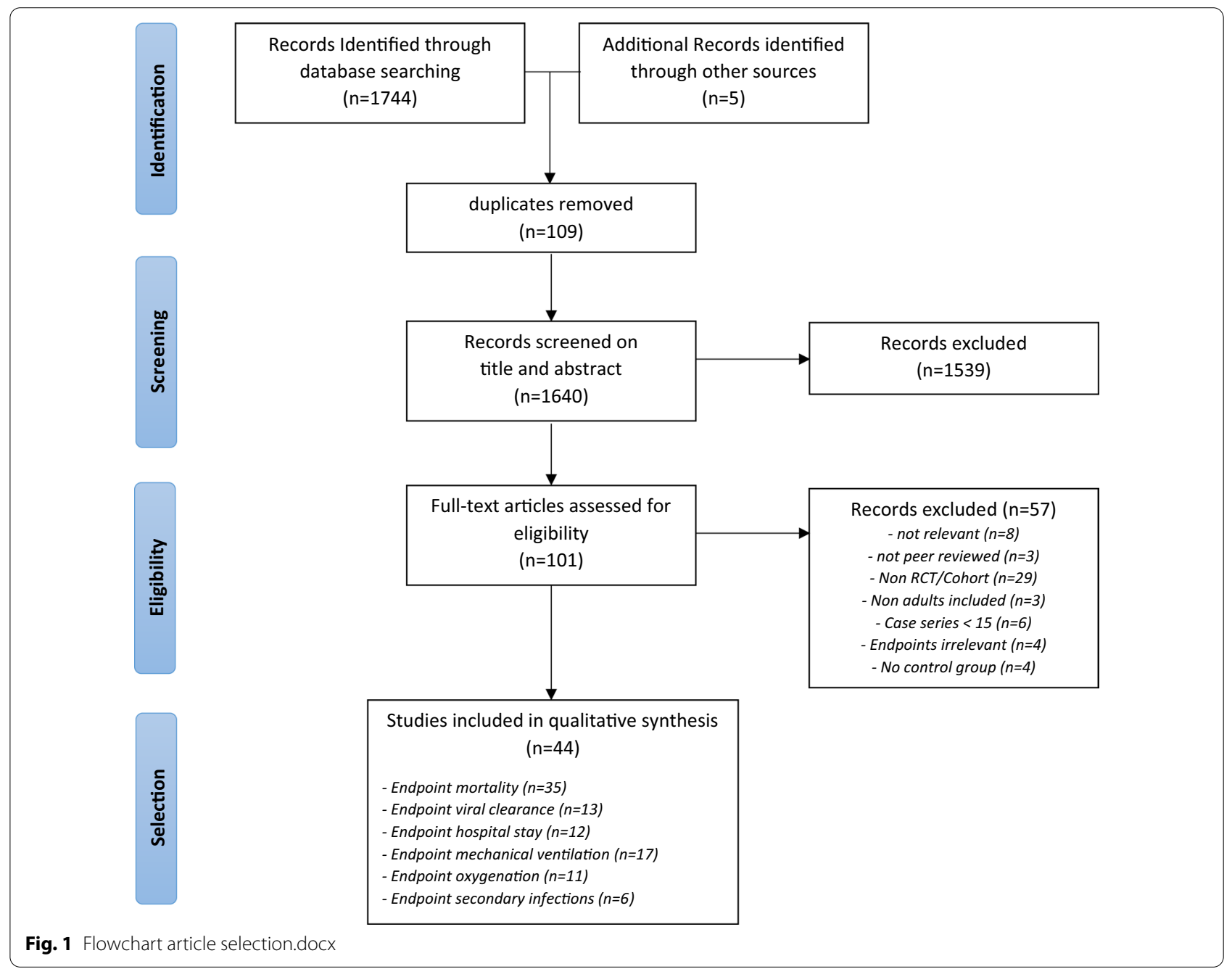

\section{Effect of steroids on primary and secondary outcomes (Table 2, Additional file 7)}

Thirty-five of 44 studies reported on Mortality. Thirteen of these could not be integrated in the meta-analysis due to only overall mortality reporting $(\mathrm{n}=5),[45,63$, $64,66,67$ ] or only descriptive reporting $(n=8)$, i.e., of a trend toward better outcome $(\mathrm{n}=3),[42,68,69]$, no effect $(n=3)[44,49,65]$ or negative effect on outcome $(n=2)[50,52]$. For the remainder of 22 studies, a pooled estimate was calculated and graphically summarized in a forest plot (Fig. 2). The mortality reported in these studies was mainly 28 -day mortality (11 studies), in six studies in-hospital mortality of shorter duration and in five studies there was an unreported follow up period (Additional file 7). The overall risk estimate (OR) was 0.72 (95\%CI 0.57-0.87), suggesting a beneficial effect of steroids use in COVID-19 patients hospitalized with moderate or severe respiratory failure on mortality.
Studies were heterogeneous (overall $\mathrm{I}^{2}$ of $51.1 \%$, $\mathrm{p}=0.002)$ with a between-study variance $\left(\mathrm{tau}^{2}\right)$ of 0.048 . For the subset of RCTs, the risk estimate was 0.84 (95\%CI $0.72-0.96)$ and $\mathrm{I}^{2}$ and $\mathrm{tau}^{2}$ were $31.2 \%(\mathrm{p}=0.213)$ and 0.0096 , corresponding to less heterogeneity and less between-study variance.

Thirteen of 44 studies reported on viral clearance, which most frequently was defined as two consecutive negative RT-PCR on nasopharyngeal swabs, or a cycle time value of 40 or more. In the corticosteroid group, viral clearance time ranged from 5 to 29 days, in the standard of care group from 8 to 24 days. In nine of 13 studies, viral shedding was delayed in the corticosteroid group. [40, 43, 46, 47, 53, 59, 63, 65, 70] In the other four studies, viral clearance was equal $(n=2)[50,71]$ or even better in the corticosteroid group $(n=2)[44$, 52]. The numbers are too small to quantify the effect of corticosteroids on viral shedding, or to compare viral shedding duration in subgroups of severity of COVID 


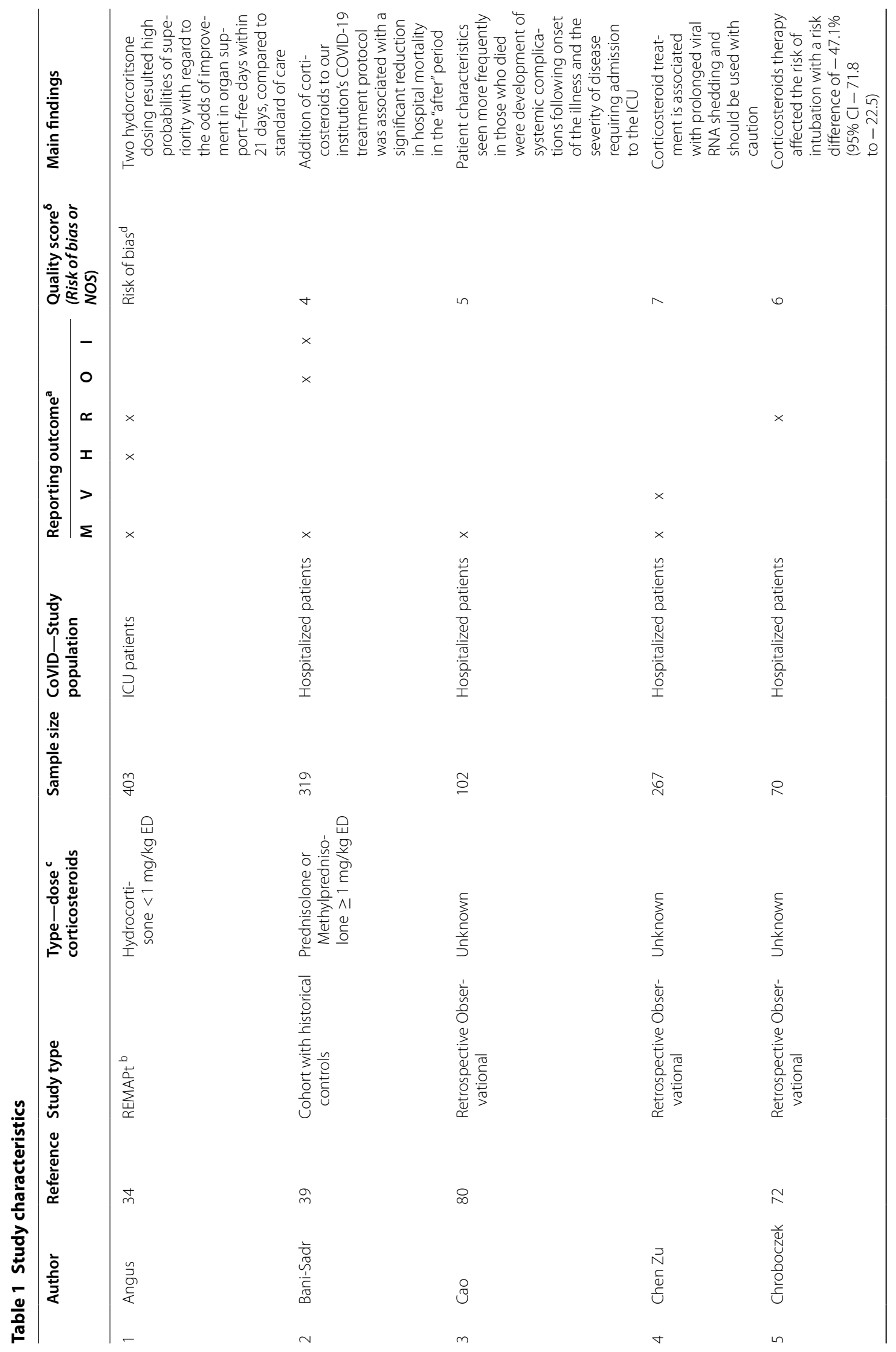




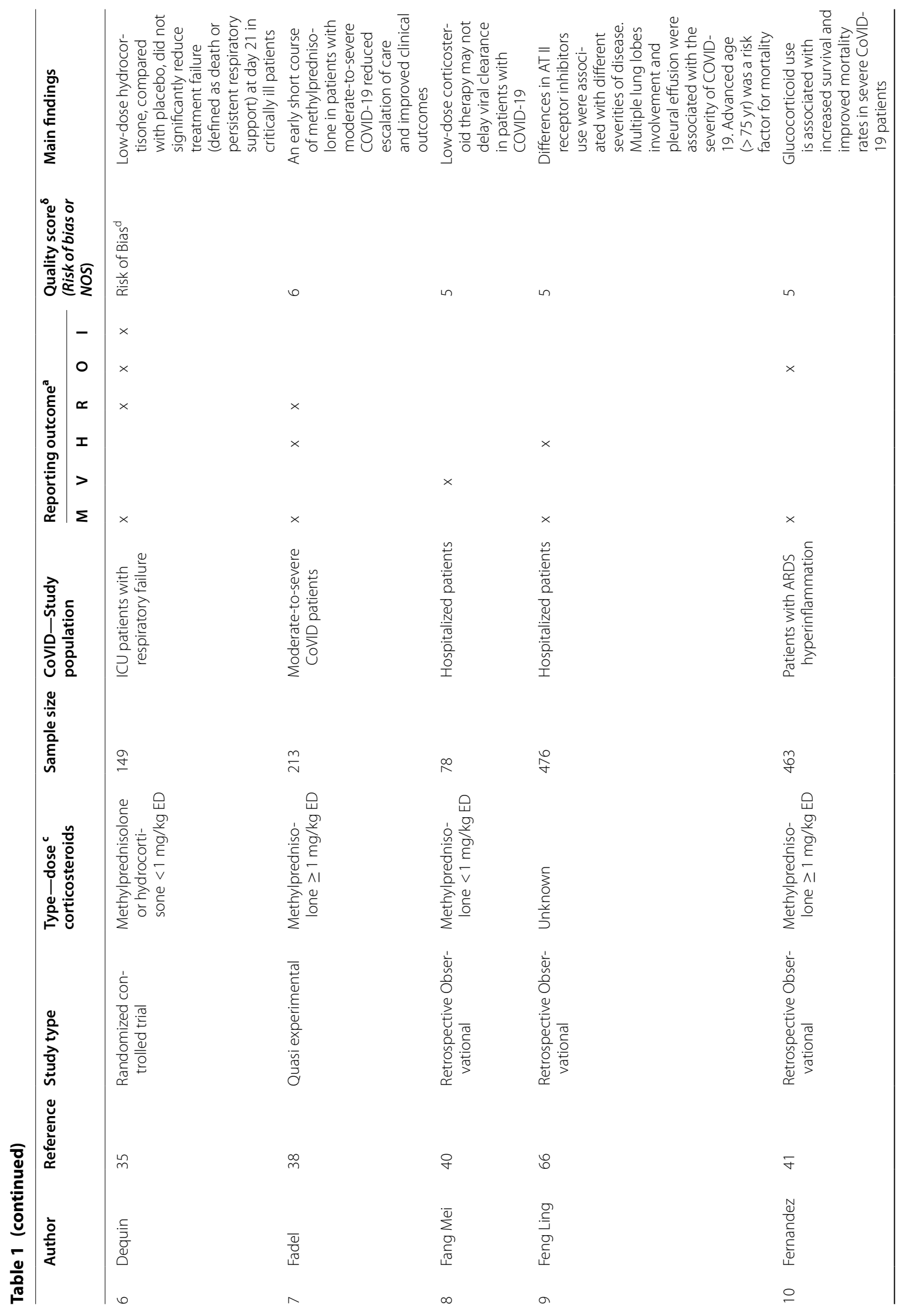




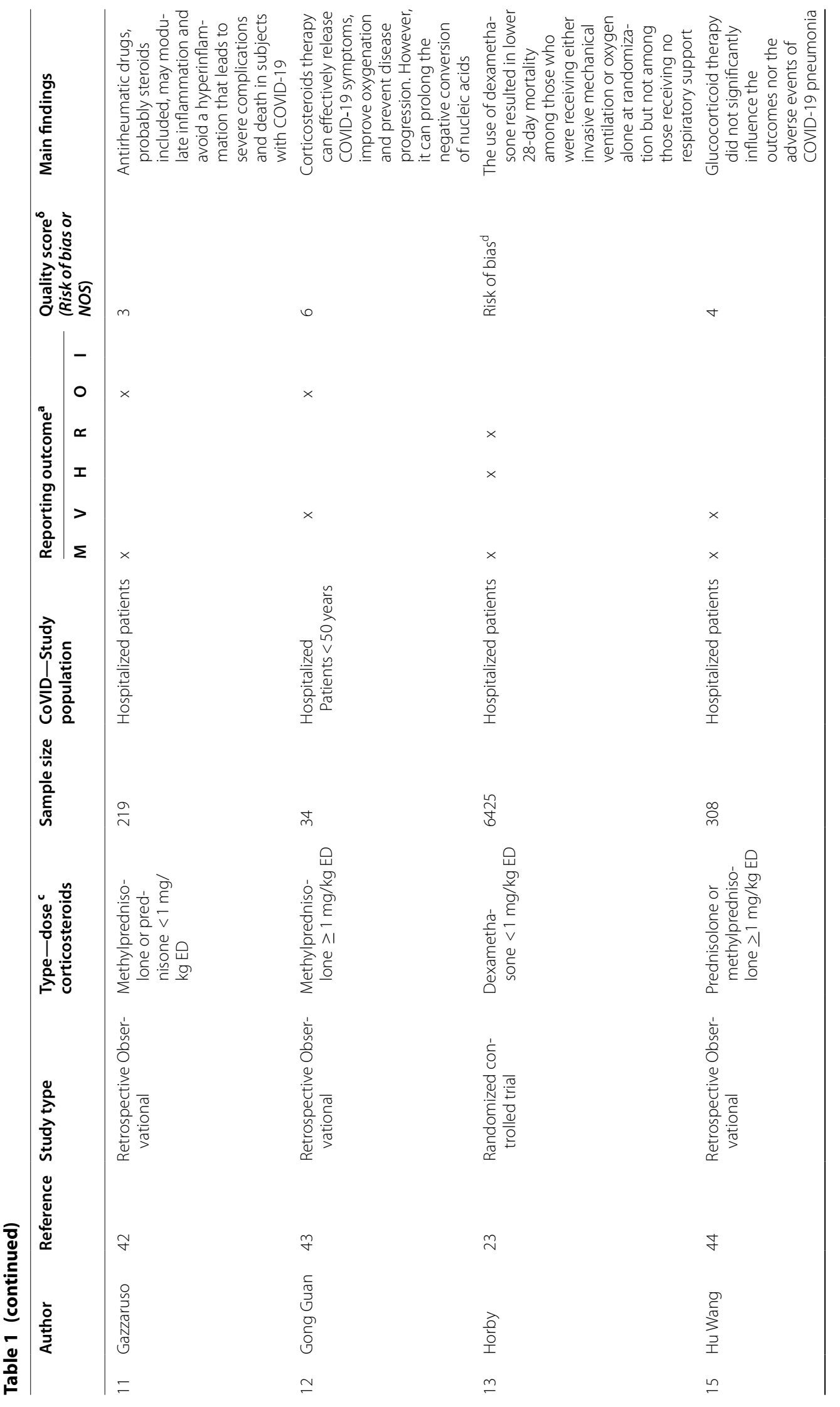




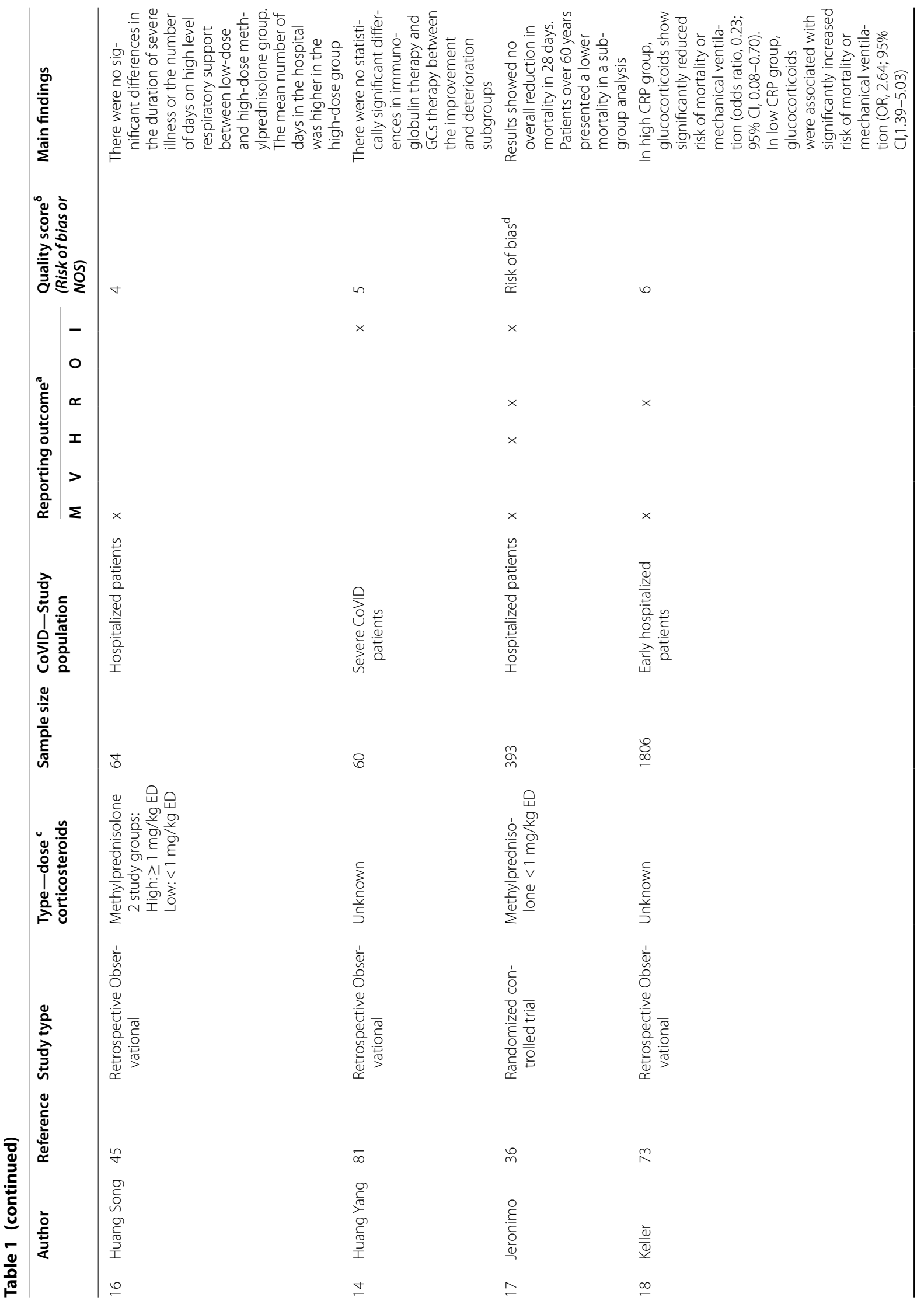




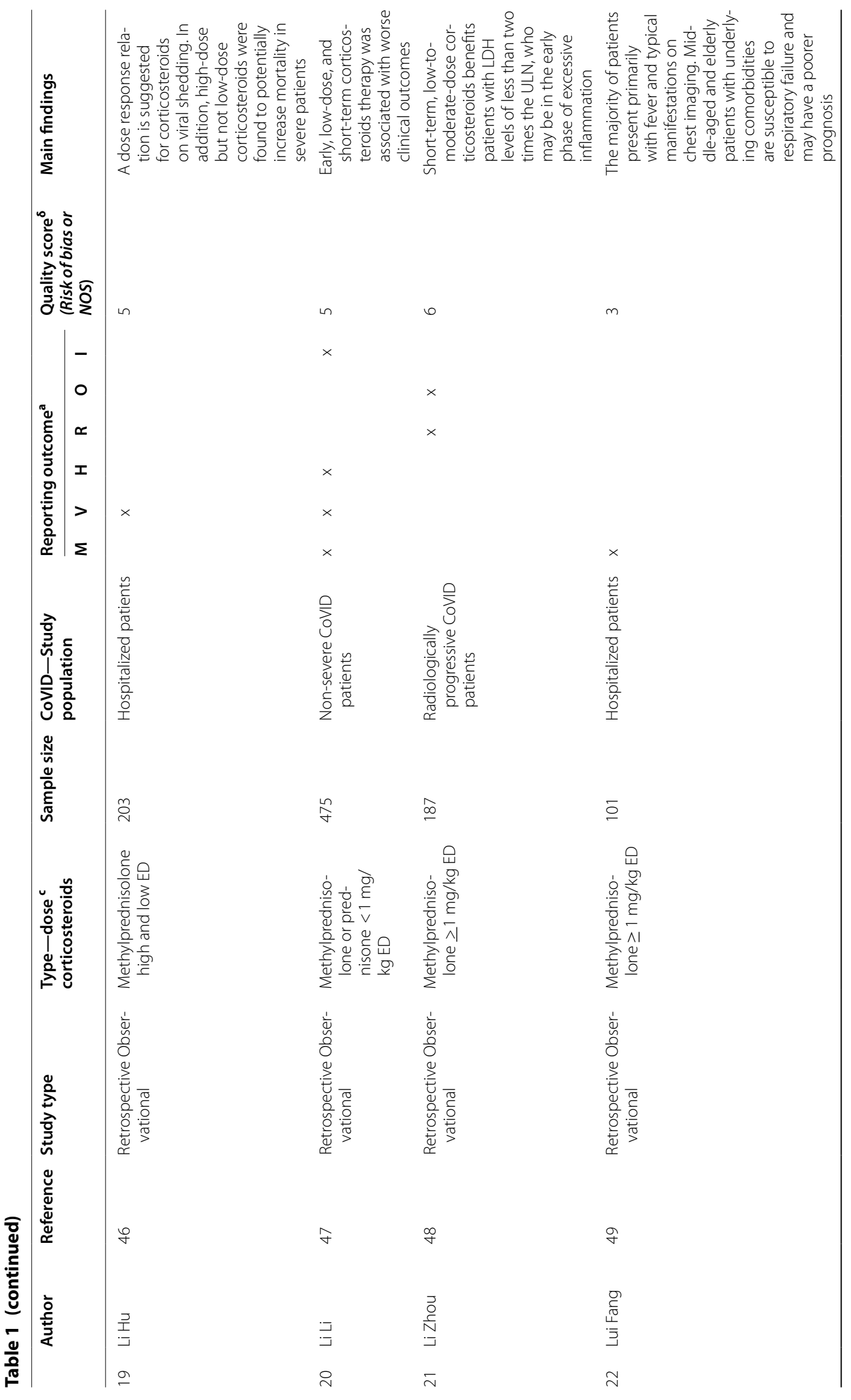




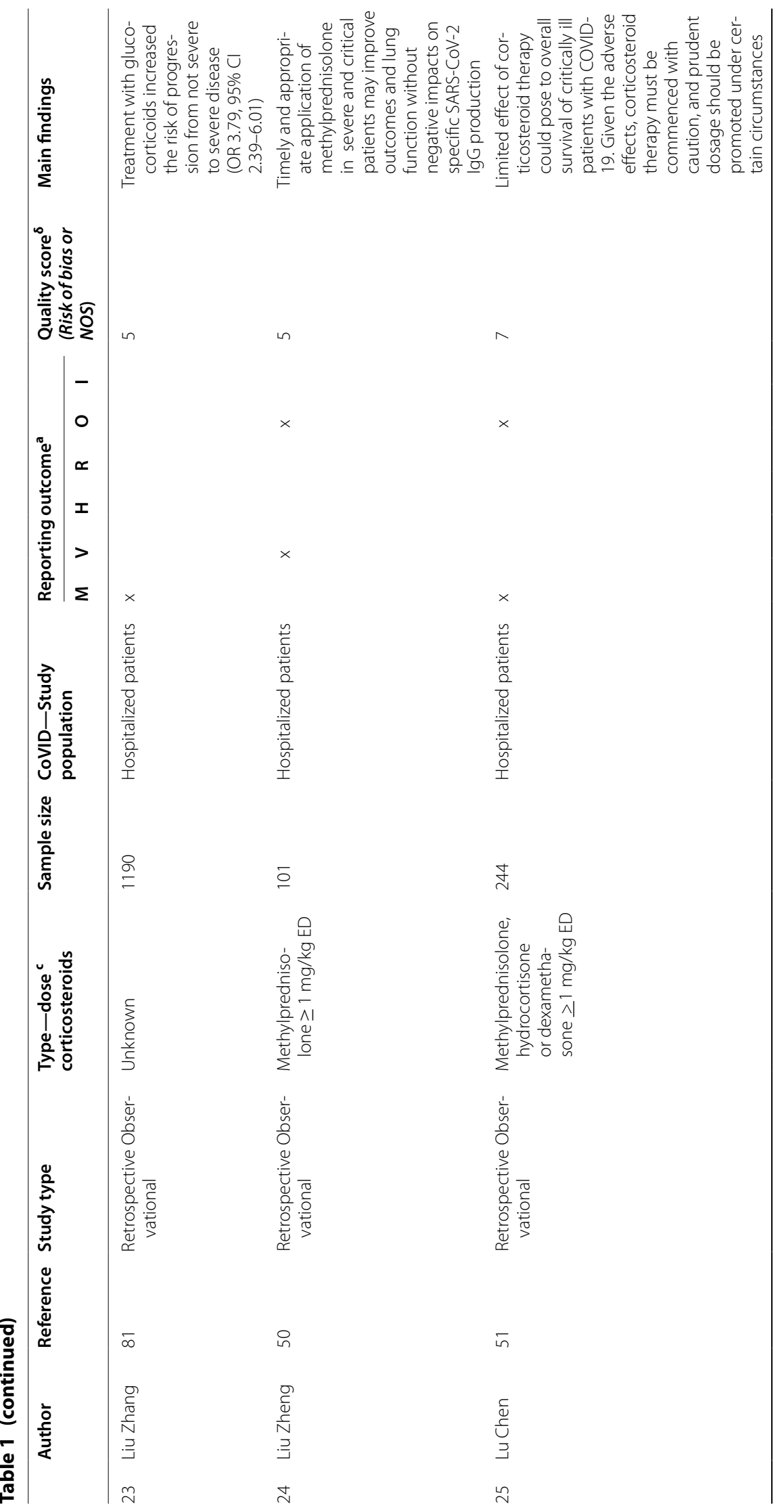




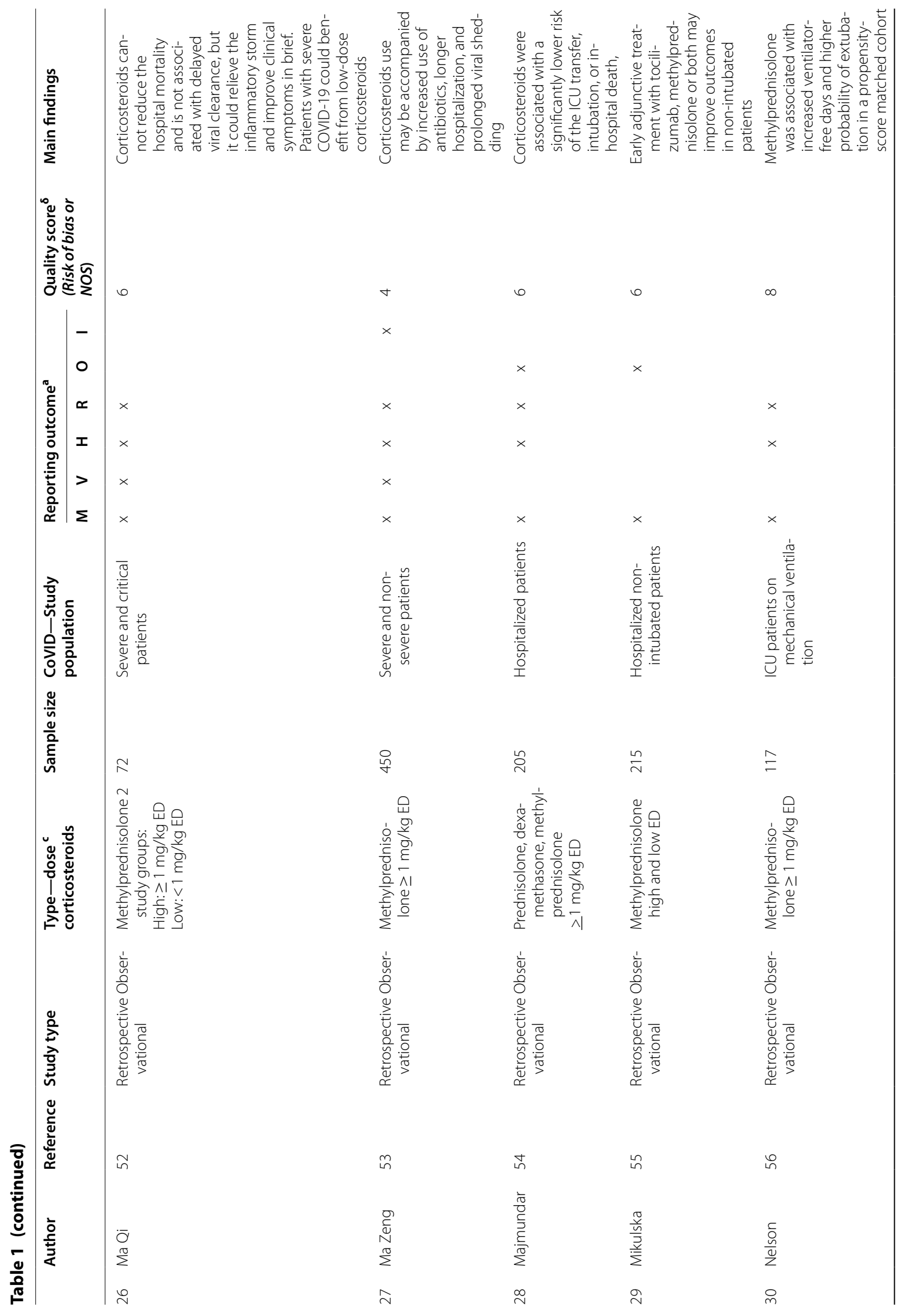




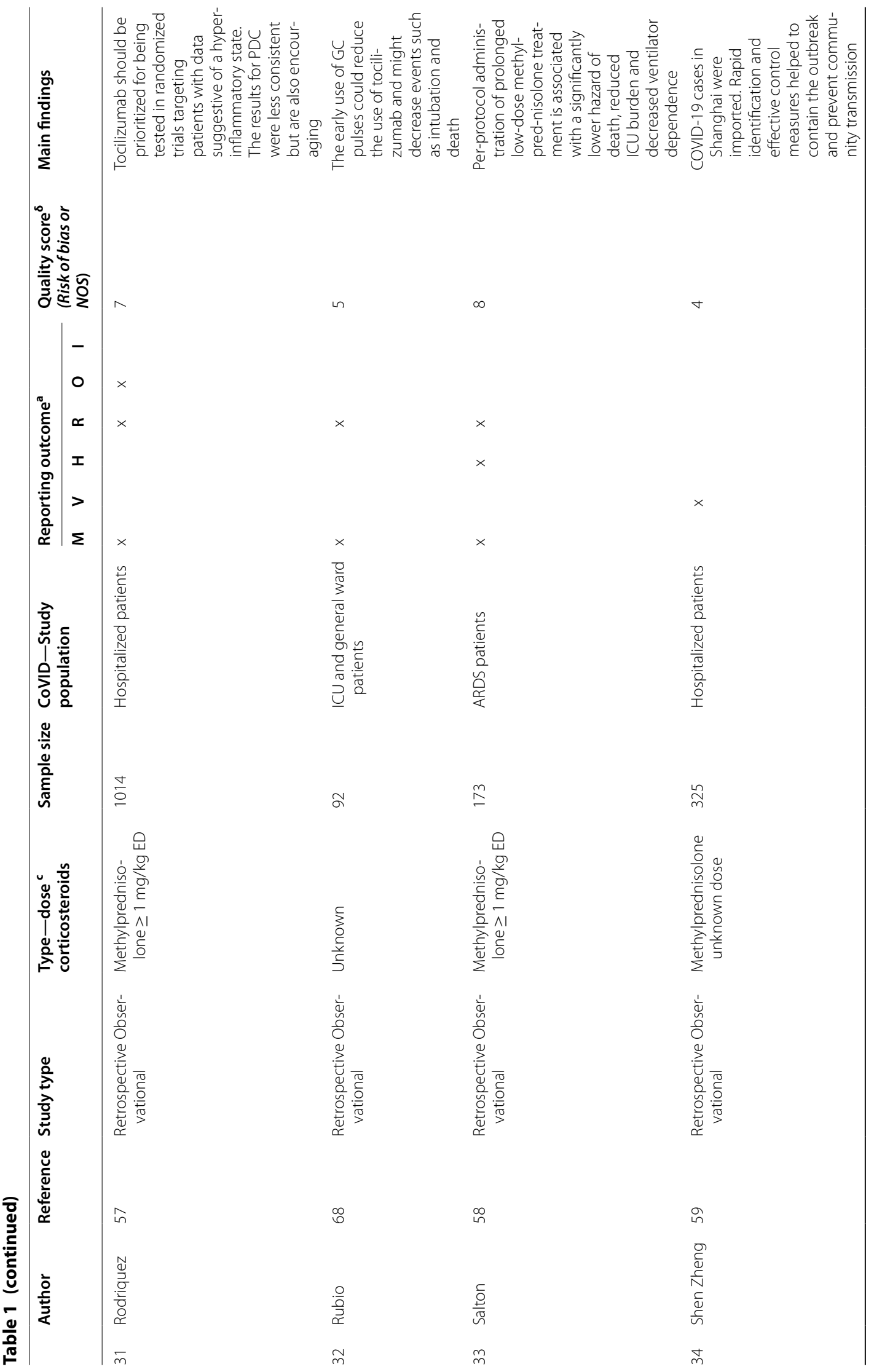




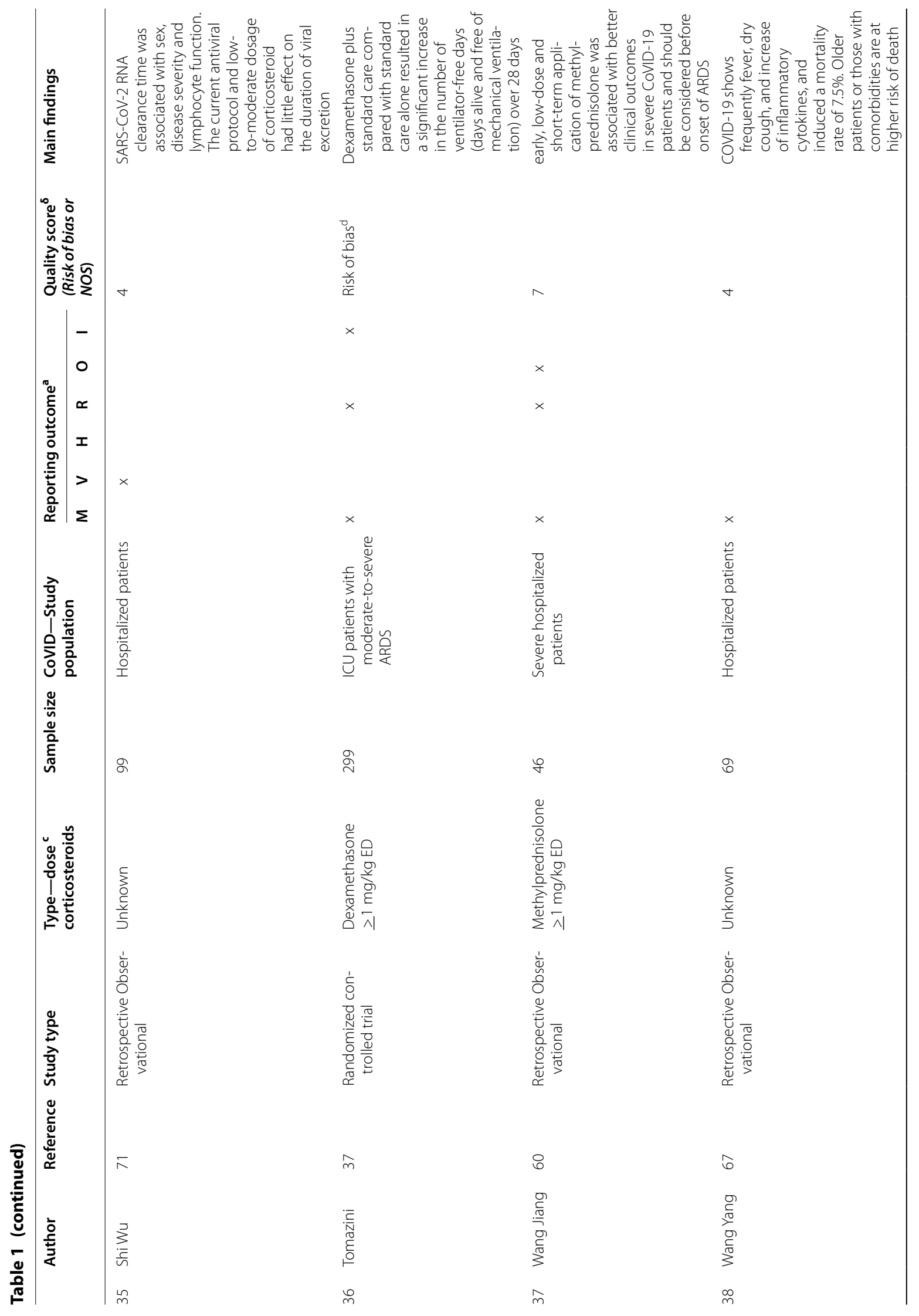




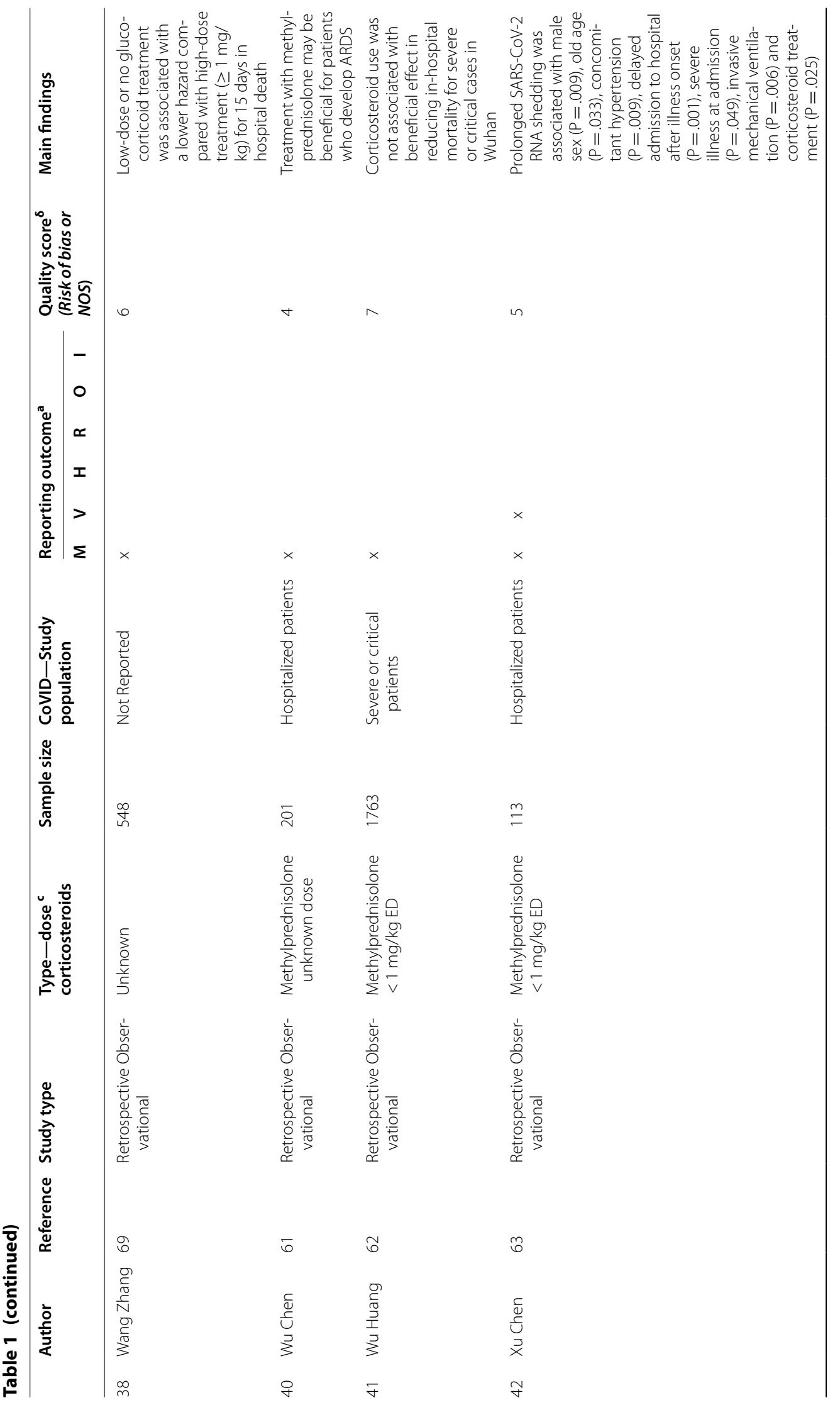




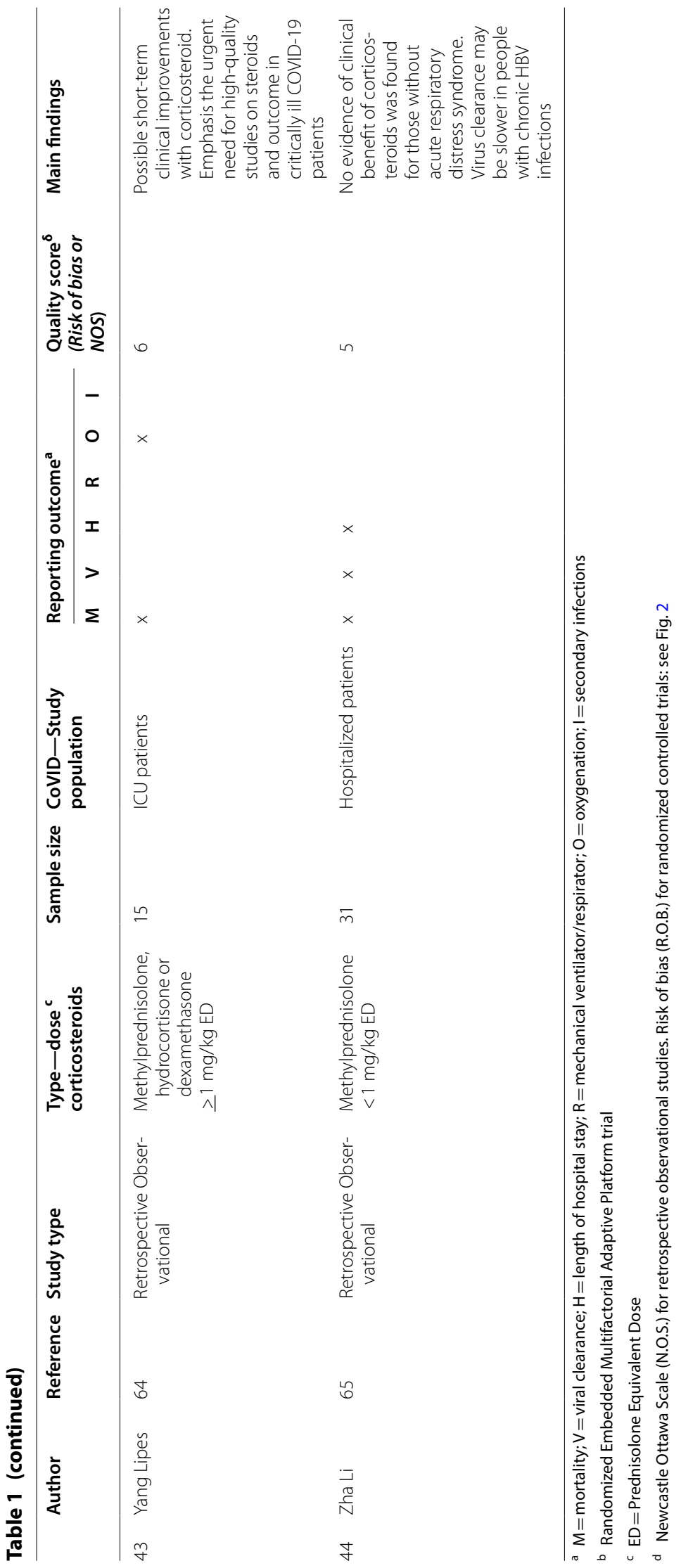




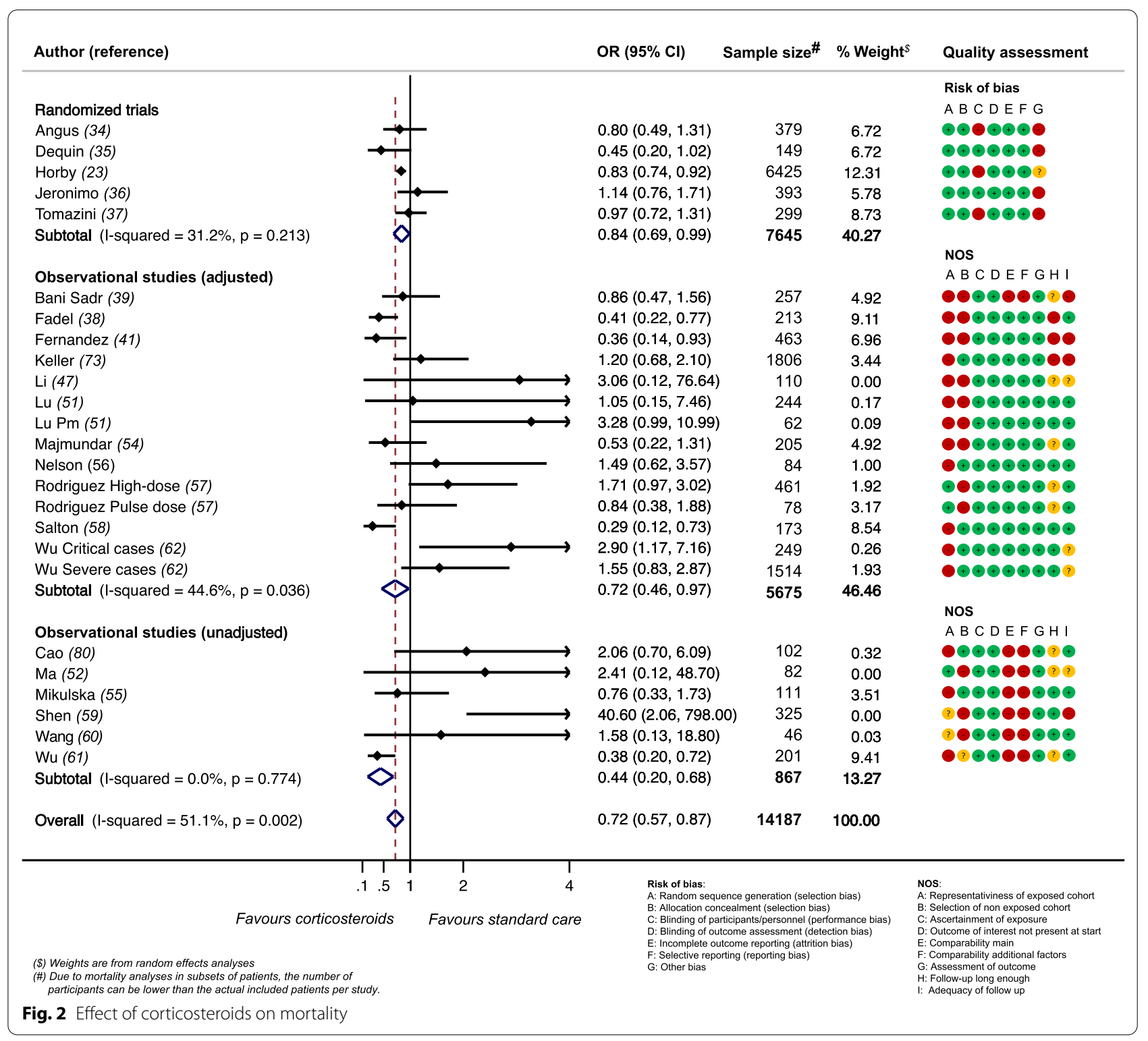

illness, dose, type or timing of corticosteroids administered. (Additional file 8).

In twelve studies, length of hospital stay was compared in corticosteroid versus non-corticosteroid groups. The outcomes varied between studies: six reported longer hospital stay in the corticosteroid group [36, 47, 53, 56, $66]$ and five reported the opposite [23, 34, 38, 52, 54] or no effect on hospital stay [58].

Fourteen of 17 studies reported a positive effect of corticosteroids on ventilator-free days [34, 37, 56], on the number of patient requiring mechanical ventilation for respiratory insufficiency $[23,35,38,48,54,57,58,60$, 68,72 ] or on the time on mechanical ventilator [52]. In the pooled analyses fewer patients required mechanical ventilation in the corticosteroids group (RR 0.71 (95\% CI 0.54-0.97) (Fig. 3) though only seven studies supplied sufficient data for this analysis. Jeronimo and Keller failed to demonstrate significant differences [36, 73] and one study reported the opposite effect [53]. The dose of corticosteroids could not be related to respiratory outcomes.

Eleven studies reported on the effect of corticosteroids on oxygenation. Various definitions were used: liters per minute of oxygen needed, oxygen saturation, $\mathrm{PaO}_{2} / \mathrm{FiO}_{2}$ ratio. The effect of corticosteroids on oxygenation was very heterogeneous: In four studies, there was no significant effect $[41,42,51,55]$, in three studies significant improvement was described $[50,60,64]$ and in four studies worse outcome was observed. [35, 39, 54, 57] 


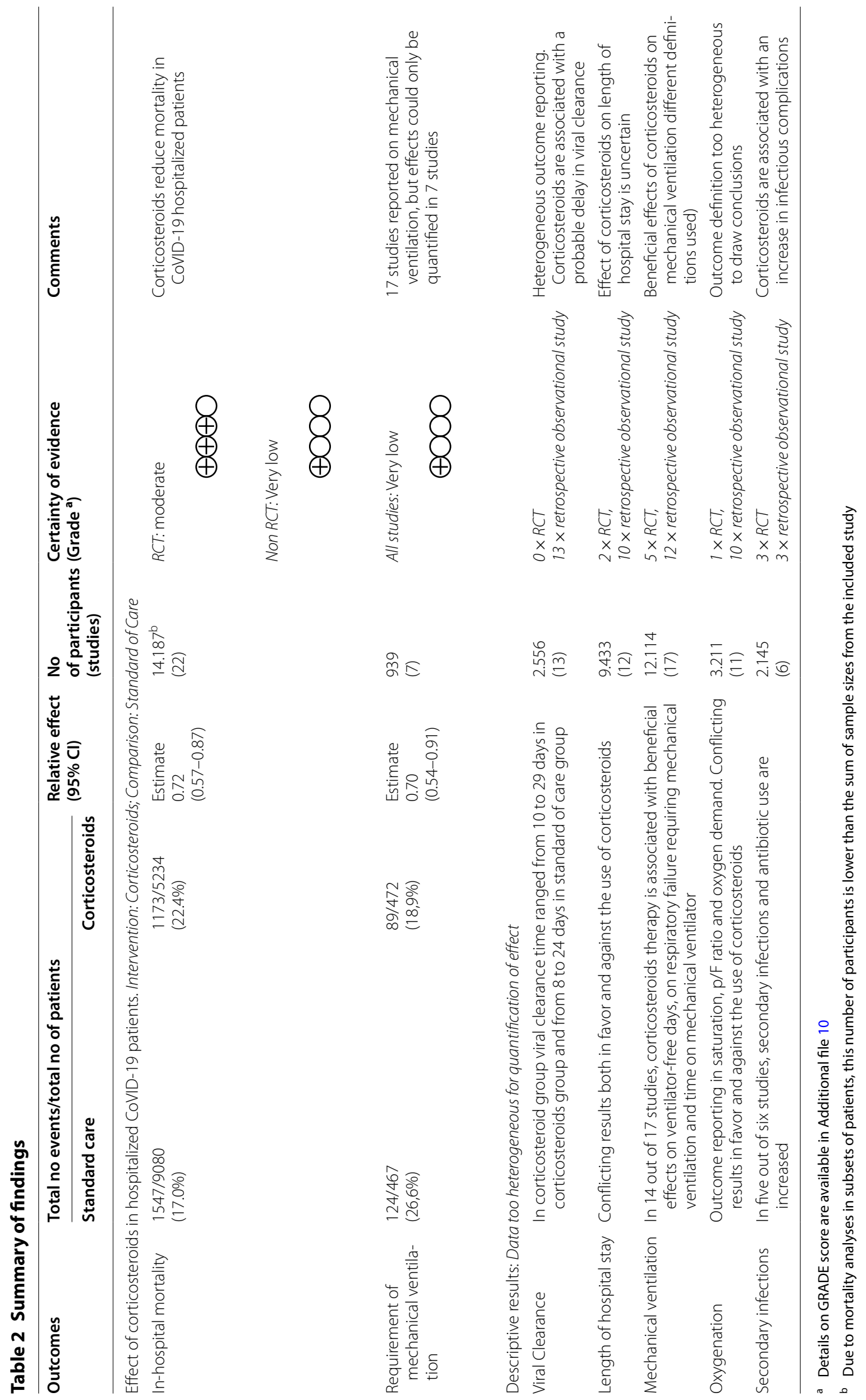




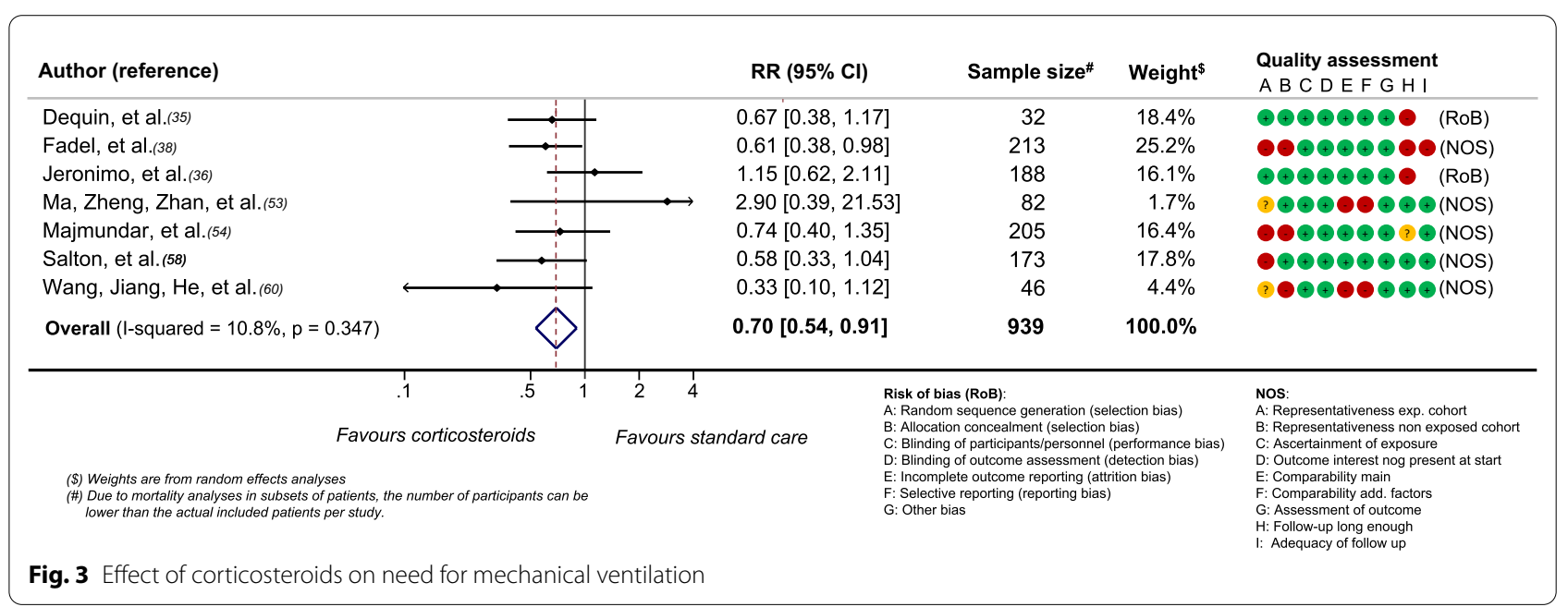

Six studies addressed secondary infections. More frequently broad spectrum antibiotics were used in the corticosteroid group [39, 47, 53] and more secondary infections or sepsis episodes were described [35, 36]. Only Tomazini found a lower percentage of secondary infections in the corticosteroid group [37]. A dose effect of steroids on development of infections or antibiotic need could not be demonstrated.

\section{Discussion}

In this systematic review and meta-analysis on effectiveness and safety of corticosteroids in COVID-19 patients, the pooled estimate of the observational retrospective studies and the RCTs supported the positive effect of corticosteroids therapy on mortality in COVID-19 disease as first reported in the RECOVERY trial. [23] Furthermore, in already respiratory compromised COVID-19 patients, the need for mechanical ventilation was lower in corticosteroid treated COVID-19 patients. And although data in the studies were too sparse to draw any firm conclusions, there might be a signal of delayed viral clearance and an increase in antibiotic use and infections in the corticosteroid group. However, this did not seem to lead to prolonged hospital stay or increased mortality.

Besides reviews extrapolating knowledge on SARSCoV or MERS-CoV [21] or on non-viral ARDS [4], or combining studies on SARS-CoV and MERS-CoV $[2,18$, $74]$, to our knowledge, only three other meta-analyses on this subject were conducted with the conflicting results. $[24,75,76]$ Sarkar et al. found low-quality evidence with high variability, showing that in patients with COVID-19 corticosteroids may be associated with an around twofold increase in mortality [75]. Tlayjeh et al. [76] found no significant difference in mortality or mechanical ventilation need, at the cost of a prolonged viral clearance time. The investigators explained that the discordance in studies was due to bias in the large number of non-RCTs. In the third, very robust, prospective meta-analysis of published and pending trials (inclusion has pretty much stopped since the recovery trial was published), Sterne et al. [24], found that in critically ill patients with COVID-19, the administration of systemic corticosteroids, compared with usual care or placebo, was associated with lower 28-day all-cause mortality. A downside of this rather robust study was that almost 60 percent of the population consisted of the RECOVERY study population and a reasonable amount of data was generated from unpublished, unfinished studies.

Compared to these other systematic reviews on corticosteroids and COVID-19, ours was able to include the largest number of studies and COVID-19 patients. Furthermore, we included both observational studies and RCTs to be able to assess adverse effects such as viral clearance and risk of infections. To obtain the highest possible quality, we excluded non-peer reviewed prepublished manuscripts and furthermore, if available, we included adjusted estimates in the meta-analysis, reducing bias by incongruent study groups (Additional file 9).

Our review has several limitations. The first is that we retrospectively registered our systematic review and meta-analysis. Indeed, it is very important, especially in COVID-19 pandemic times with a high number of publications on COVID-19, to register beforehand to avoid redundancy and inefficiency and to prevent flooding. The review arose from a clinical point of view to gather all literature on corticosteroids and COVID-19, as we clinicians were in doubt whom to administer this drug to. Doing so, we thought it would be best to summarize our findings in a review, since we presumed other clinicians would be struggling with the same questions. 
Furthermore, most of the included studies were retrospective cohort studies with increased risk of bias and lower level of evidence, as we confirmed by the GRADE classification (Table 2, Additional file 10). Besides that, large heterogeneity in the studies was present (i.e., study population, type, dose, initiation and duration of corticosteroids and outcome measures) and we emphasize that definitions of primary and secondary outcome measures varied substantially per included article and pooled data from this review should be interpreted cautiously. However, we decided beforehand to only include shortterm mortality, i.e., 28-day or closely related short-term in-hospital mortality. Furthermore, we decided to carefully note the applied definitions in the studies in our data extraction tables and include only outcomes as defined by the investigators if they filled our inclusions criteria. We agree that the remaining variation in definitions is indeed a drawback of this review. And although the pooled data from this review should therefore be interpreted cautiously, they represent the effect of corticosteroids on short-term 28-day mortality and the pooled estimates for RCTs and adjusted and unadjusted observational studies pointed toward the same direction, i.e., of a beneficial effect. In many studies, confounding by indication was evidently present: two studies described that corticosteroid administration was "at the discretion of the treating physician" [40, 41] and four reported that severe patients were more likely to receive corticosteroid treatment. [40, 49, 60, 66] Many studies had incomplete followup and a considerable amount of patients did not reach definite endpoints. However, our conscious exclusion of non-peer-reviewed studies, the focus on a measurable and quantifiable endpoint, and, if possible, inclusion of risk estimates corrected for confounders and propensity matched, increased the validity of the retrospective evidence supporting the RECOVERY trial. Furthermore, from the included studies, 26 originated in China, with 13 from the hotspot regions (Wuhan, Hubei and Shanghai). This might impair generalizability but although overlapping study populations were present within the included studies (see table in Additional file 4.), this was only incidentally the case for secondary outcome measures. For the main outcome, multiple publication bias was unlikely (Additional file 11). Furthermore, $42 \%$ of the study population was included from outside China. Moreover, in terms of generalizability, the median age from the included patients in this review ranged from 34 to 72 years. However, data from the CDC state that $42.9 \%$ of hospitalized patients in the USA are $>65$ years and European numbers from the European Centre for Disease Prevention and Control (ECDC) show that 54.2\% hospitalized patients are $>65$ years with great variation between countries. [77, 78] Despite aforementioned limitations, still, this systematic review and meta-analysis confirms the conclusion of the meta-analysis of the RCTs that critically ill COVID-19 patients hospitalized for moderate or severe respiratory failure, with or without mechanical ventilation, should receive corticosteroids.

Severe COVID-19 patients are faced with a twofold problem. On the one hand, there is the hyperinflammatory response, resulting in pulmonary thrombosis, extravasation of cell debris and acute lung injury or even ARDS [79]. On the other hand, there is a need to clear the viral infection itself. This primary phenomenon suggests a possible target for corticosteroids [17]. Thus, the confirmation that there is predominantly a beneficial effect of corticosteroids on mortality is congruent with pathophysiological reasoning and prior knowledge. In our study we, found a signal of delayed viral clearance, but data in the studies were too sparse to draw any firm conclusions. Therefore, what is lacking is knowledge on the optimal start of corticosteroid administration after the start of illness, specific subpopulations and type, dose and duration of corticosteroids. RCTs so far reported a strongly beneficial effect on mortality but did not investigate optimal timing and indication of corticosteroid administration [24], and our study was not able to provide an answer to the latter issues, either. Therefore, future research should focus on which patient characteristics, laboratory and radiological markers can be used to guide indication and timing of corticosteroid treatment, particularly in relation to safety (e.g., delayed viral clearance and increased incidence of secondary infections).

\section{Conclusion}

Our findings from both observational studies and RCTs confirm a beneficial effect of corticosteroids on shortterm mortality and a reduction in the need for mechanical ventilation. And although data in the studies were too sparse to draw any firm conclusions, there might be a signal of delayed viral clearance and an increase in secondary infections related to corticosteroid use. Optimal timing, dose and duration of corticosteroids, in relation to safety, remain subject for further investigation. Since corticosteroids are affordable and easily accessible in healthcare systems quivering under the pressure of the global outbreak of this rapidly spreading coronavirus, this field of research should be a universal priority.

\section{Supplementary information}

Supplementary information accompanies this paper at https://doi. org/10.1186/s13054-020-03400-9.

Additional file 1. Search strategy.

Additional file 2. Data extraction form

Additional file 3. Excluded references. 


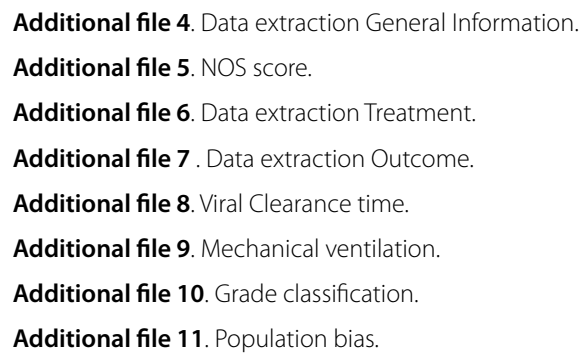

\section{Abbreviations}

ARDS: Acute respiratory distress syndrome; CDC: Centers for Disease Control and Prevention; Cl: Confidence interval; COVID-19: Coronavirus disease 2019; CT: Computed tomography; ECDC: European Centre for Disease Prevention and Control; FiO2: Inspiratory oxygen fraction; HR: Hazard ratio; ICU: Intensive care Unit; IQR: Interquartile range; LOS: Length of stay; MERS-CoV: Middle East respiratory syndrome coronavirus; OR: Odds ratio; NOS: Newcastle Ottawa Scale; NR: Not reported; OR: Odds ratio; PaO2: Arterial oxygen tension; PRISMA: Preferred Reporting Items for Systematic Reviews and Meta-Analyses; RNA: Ribonucleic acid; RR: Rate ratio; RT-PCR: Reverse transcription polymerase chain reaction; SARS-CoV: Severe acute respiratory syndrome coronavirus; SD: Standard deviation; Steroids: Glucocorticoids or corticoids; SpO2: Plasma oxygen saturation; WHO: World Health Organization.

\section{Acknowledgements}

We would like to express our gratitude to C. Pees, librarian, for her efforts in designing the search strategies used in collecting data. We would also like to express our gratitude to Olaf M. Dekkers for his aid in the statistical analysis, i.e., calculating pooled estimate and constructing the forest plots.

\section{Authors' contributions}

SA created the study project. JVP, JV, PB, EH, KN and SA extracted and analyzed the data. JVP and SA performed the statistical analyses with the aid of OD (in acknowledgements). JVP, PB, EH, KN and SA wrote the draft and all co-authors critically revised the manuscript and approved the final version for publication. All authors have read and approved the final manuscript.

\section{Funding}

Not applicable.

\section{Availability of data and materials \\ Not applicable.}

\section{Ethics approval and consent to participate}

Not applicable.

\section{Consent for publication}

Not applicable.

\section{Competing interests}

All persons who meet authorship criteria are listed as authors. The manuscript has been seen and approved by all authors. On behalf of all authors, the corresponding author states that there is no conflict of interest.

\section{Author details}

${ }^{1}$ Department of Intensive Care, Leiden University Medical Center, Albinusdreef 2, 2333 ZA Leiden, The Netherlands. ${ }^{2}$ Faculty of Medicine, Leiden University Medical Center, Leiden, The Netherlands. ${ }^{3}$ Department of Clinical Epidemiology, Leiden University Medical Center, Leiden, The Netherlands.

Received: 31 July 2020 Accepted: 19 November 2020

Published online: 14 December 2020

\section{References}

1. European Centre for Disease Prevention and Control. Accessed October 14, 2020 at https://www.ecdc.europa.eu/en/geographical-distributi on-2019-ncov-cases

2. Li H, Chen C, Hu F, et al. Impact of corticosteroid therapy on outcomes of persons with SARS-CoV-2, SARS-CoV, or MERS-CoV infection: a systematic review and meta-analysis. Leukemia. 2020;34(6):1503-11.

3. Wang C, Horby PW, Hayden FG, Gao GF. A novel coronavirus outbreak of global health concern. Lancet. 2020;395(10223):470-3.

4. Villar J, Confalonieri M, Pastores SM, et al. Rationale for prolonged corticosteroid treatment in the acute respiratory distress syndrome caused by coronavirus disease 2019. Crit Care Explor. 2020;2(4):e0111.

5. Zhou F, Yu T, Du R, et al. Clinical course and risk factors for mortality of adult inpatients with COVID-19 in Wuhan, China: a retrospective cohort study. Lancet. 2020;395(10229):1054-62.

6. Grasselli G, Zangrillo A, Zanella A, et al. Baseline characteristics and outcomes of 1591 patients infected with SARS-CoV-2 admitted to ICUs of the Lombardy region. Italy JAMA. 2020;323(16):1574-81.

7. Yang X, Yu Y, Xu J, et al. Clinical course and outcomes of critically ill patients with SARS-CoV-2 pneumonia in Wuhan, China: a singlecentered, retrospective, observational study. Lancet Respir Med. 2020;8(5):475-81.

8. Ziehr DR, Alladina J, Petri CR, et al. Respiratory Pathophysiology of Mechanically Ventilated Patients with COVID-19: A Cohort Study. Am J Respir Crit Care Med. 2020;201(12):1560-4.

9. Guan W-j, Ni Z-y, Hu Y, et al. Clinical characteristics of coronavirus disease 2019 in China. New Engl J Med. 2020;382(18):1708-20.

10. Huang C, Wang Y, Li X, et al. Clinical features of patients infected with 2019 novel coronavirus in Wuhan, China. Lancet. 2020;395(10223):497-506.

11. Jamilloux $Y$, Henry T, Belot A, et al. Should we stimulate or suppress immune responses in COVID-19? Cytokine and anti-cytokine interventions. Autoimmun Rev. 2020;19(7):102567.

12. Channappanavar R, Perlman S. Pathogenic human coronavirus infections: causes and consequences of cytokine storm and immunopathology. Semin Immunopathol. 2017;39(5):529-39.

13. Mehta P, McAuley DF, Brown M, et al. COVID-19: consider cytokine storm syndromes and immunosuppression. Lancet. 2020;395(10229):1033-4.

14. Zhang W, Zhao Y, Zhang F, et al. The use of anti-inflammatory drugs in the treatment of people with severe coronavirus disease 2019 (COVID-19): the perspectives of clinical immunologists from China. Clin Immunol. 2020;214:108393.

15. Alijotas-Reig J, Esteve-Valverde E, Belizna C, et al. Immunomodulatory therapy for the management of severe COVID-19. Beyond the anti-viral therapy: a comprehensive review. Autoimmun Rev. 2020;19(7):102569.

16. Jiang S, Liu T, Hu Y, et al. Efficacy and safety of glucocorticoids in the treatment of severe community-acquired pneumonia: a meta-analysis. Medicine (Baltimore). 2019;98(26):e16239.

17. Villar J, Ferrando C, Martínez D, et al. Dexamethasone treatment for the acute respiratory distress syndrome: a multicentre, randomised controlled trial. Lancet Respir Med. 2020;8(3):267-76.

18. Singh AK, Majumdar S, Singh R, et al. Role of corticosteroid in the management of COVID-19: A systemic review and a Clinician's perspective. Diabetes Metab Syndr. 2020;14(5):971-8.

19. Veronese N, Demurtas J, Yang L, et al. Use of corticosteroids in coronavirus disease 2019 pneumonia: a systematic review of the literature. Front Med (Lausanne). 2020;7:170.

20. Arabi YM, Mandourah Y, Al-Hameed F, et al. Corticosteroid therapy for critically ill patients with Middle East Respiratory Syndrome. Am J Respir Crit Care Med. 2018;197(6):757-67.

21. Russell CD, Millar JE, Baillie JK. Clinical evidence does not support corticosteroid treatment for 2019-nCoV lung injury. Lancet. 2020;395(10223):473-5.

22. Stockman LJ, Bellamy R, Garner P. SARS: systematic review of treatment effects. PLoS Med. 2006;3(9):e343.

23. Horby P, Lim WS, Emberson JR, et al. Dexamethasone in hospitalized patients with covid-19: preliminary report. N Engl J Med. 2020. https:// doi.org/10.1056/NEJMoa2021436.

24. Sterne JAC, Murthy S, Diaz JV, et al. Association between administration of systemic corticosteroids and mortality among critically III patients with COVID-19: a meta-analysis. JAMA. 2020. 
25. World Health Organization. Accessed October 14, 2020 at https://www. who.int/publications/i/item/clinical-management-of-covid-19

26. Alhazzani W, Møller MH, Arabi YM, et al. Surviving Sepsis Campaign: guidelines on the management of critically ill adults with Coronavirus Disease 2019 (COVID-19). Intensive Care Med. 2020;46(5):854-87.

27. Moher D, Shamseer L, Clarke M, et al. Preferred reporting items for systematic review and meta-analysis protocols (PRISMA-P) 2015 statement. Syst Rev. 2015;4(1):1.

28. Sterne JA, Gavaghan D, Egger M. Publication and related bias in metaanalysis: power of statistical tests and prevalence in the literature. J Clin Epidemiol. 2000;53(11):1119-29.

29. Dekkers OM. Meta-analysis: key features, potentials and misunderstandings. Res Pract Thromb Haemost. 2018;2(4):658-63.

30. Higgins JP, Altman DG, Gøtzsche PC, et al. The Cochrane Collaboration's tool for assessing risk of bias in randomised trials. BMJ. 2011;18(343):d5928.

31. Coding manual for case-control studies. GA Wells BS, D O'Connell, J Peterson, et al. Accessed October 18, 2020 at http://www.ohri.ca/progr ams/clinical_epidemiology/nos_manual.pdf

32. Newcastle-Ottowa quality assessment scale case control studies. GA Wells BS, D O'Connell, J Peterson, et al. Accessed at Octobre 18, 2020 at http://www.ohri.ca/programs/clinical_epidemiology/nosgen.pdf

33. Egger M, Smith GD, Phillips AN. Meta-analysis: principles and procedures. BMJ. 1997;315:1533-7.

34. Angus DC, Derde L, Al-Beidh F, et al. Effect of hydrocortisone on mortality and organ support in patients with severe COVID-19: the REMAP-CAP COVID-19 corticosteroid domain randomized clinical trial. JAMA. 2020;324(13):1317-29.

35. Dequin PF, Heming N, Meziani F, et al. Effect of hydrocortisone on 21-day mortality or respiratory support among critically ill patients with COVID-19: a randomized clinical trial. JAMA. 2020;324(13):1-9.

36. Jeronimo CMP, Farias MEL, Val FFA, et al. Methylprednisolone as adjunctive therapy for patients hospitalized with COVID-19 (metcovid): a randomised, double-blind, phase $\mathrm{Ilb}$, placebo-controlled trial. Clin Infect Dis. 2020.

37. Tomazini BM, Maia IS, Cavalcanti AB, et al. Effect of dexamethasone on days alive and ventilator-free in patients with moderate or severe acute respiratory distress syndrome and COVID-19: the CODEX randomized clinical trial. JAMA. 2020.

38. Fadel R, Morrison AR, Vahia A, et al. Early short course corticosteroids in hospitalized patients with COVID-19. Clin Infect Dis. 2020. https://doi. org/10.1093/cid/ciaa601.

39. Bani-Sadr F, Hentzien M, Pascard M, et al. Corticosteroid therapy for patients with COVID-19 pneumonia: a before-after study. Int J Antimicrob Agents. 2020;56(2):106077.

40. Fang X, Mei Q, Yang T, et al. Low-dose corticosteroid therapy does not delay viral clearance in patients with COVID-19. J Infect. 2020;81(1):147-78.

41. Fernández-Cruz A, Ruiz-Antorán B, Muñoz-Gómez A, et al. A retrospective controlled cohort study of the impact of glucocorticoid treatment in SARS-CoV-2 infection mortality. Antimicrob Agents Chemother. 2020;64:9.

42. Gazzaruso C, Carlo Stella N, Mariani G, et al. Impact of anti-rheumatic drugs and steroids on clinical course and prognosis of COVID-19. Clin Rheumatol. 2020;39(8):2475-7.

43. Gong Y, Guan L, Jin Z, et al. Effects of methylprednisolone use on viral genomic nucleic acid negative conversion and $C T$ imaging lesion absorption in COVID-19 patients under 50 years old. J Med Virol. 2020.

44. Hu Y, Wang T, Hu Z, et al. Clinical efficacy of glucocorticoid on the treatment of patients with COVID-19 pneumonia: a single-center experience. Biomed Pharmacother. 2020;130:110529.

45. Huang $H$, Song B, Xu Z, et al. Predictors of coronavirus disease 2019 severity: a retrospective study of 64 cases. Jpn J Infect Dis. 2020

46. Li Q, Li W, Jin Y, et al. Efficacy evaluation of early, low-dose, short-term corticosteroids in adults hospitalized with non-severe COVID-19 pneumonia: a retrospective cohort study. Infect Dis Therapy. 2020.

47. Li S, Hu Z, Song X. High-dose but not low-dose corticosteroids potentially delay viral shedding of patients with COVID-19. Clin Infect Dis. 2020.

48. Li Y, Zhou X, Li T, et al. Corticosteroid prevents COVID-19 progression within its therapeutic window: a multicentre, proof-of-concept, observational study. Emerg Microbes Infect. 2020;9(1):1869-77.
49. Liu J, Zheng X, Huang Y, et al. Successful use of methylprednisolone for treating severe COVID-19. J Allergy Clin Immunol. 2020;146(2):325-7.

50. Liu K, Fang Y-Y, Deng Y, et al. Clinical characteristics of novel coronavirus cases in tertiary hospitals in Hubei Province. Chin Med J (Engl). 2020;133(9):1025-31.

51. Lu X, Chen T, Wang Y, et al. Adjuvant corticosteroid therapy for critically ill patients with COVID-19. Crit Care. 2020;24(1):241.

52. Ma Q, Qi D, Deng XY, et al. Corticosteroid therapy for patients with severe novel Coronavirus disease 2019. Eur Rev Med Pharmacol Sci. 2020;24(15):8194-201.

53. Ma Y, Zeng H, Zhan Z, et al. Corticosteroid use in the treatment of COVID19: a multicenter retrospective study in hunan, China. Front Pharmacol. 2020;11:1198.

54. Majmundar M, Kansara T, Lenik JM, et al. Efficacy of corticosteroids in non-intensive care unit patients with COVID-19 pneumonia from the New York Metropolitan region. PLoS ONE. 2020;15(9):e0238827.

55. Mikulska M, Nicolini LA, Signori A, et al. Tocilizumab and steroid treatment in patients with COVID-19 pneumonia. PLoS ONE. 2020;15(8):e0237831.

56. Nelson BC, Laracy J, Shoucri S, et al. Clinical outcomes associated with methylprednisolone in mechanically ventilated patients with COVID-19. Clin Infect Dis. 2020.

57. Rodríguez-Baño J, Pachón J, Carratalà J, et al. Treatment with tocilizumab or corticosteroids for COVID-19 patients with hyperinflammatory state: a multicentre cohort study (SAM-COVID-19). Clin Microbiol Infect. 2020.

58. Salton F, Confalonieri P, Meduri GU, et al. Prolonged low-dose methylprednisolone in patients with severe COVID-19 pneumonia. Open Forum Infect Dis. 2020;7:10.

59. Shen Y, Zheng F, Sun D, et al. Epidemiology and clinical course of COVID19 in Shanghai. China Emerg Microbes Infect. 2020;9(1):1537-45.

60. Wang $Y$, Jiang W, He Q, et al. A retrospective cohort study of methylprednisolone therapy in severe patients with COVID-19 pneumonia. Signal Transduct Target Ther. 2020;5(1):57.

61. Wu C, Chen X, Cai Y, et al. Risk factors associated with acute respiratory distress syndrome and death in patients with coronavirus disease 2019 pneumonia in Wuhan. China JAMA Intern Med. 2020;180(7):934-43.

62. Wu J, Huang J, Zhu G, et al. Systemic corticosteroids and mortality in severe and critical COVID-19 patients in Wuhan. China J Clin Endocrinol Metab. 2020;105:12

63. Xu K, Chen Y, Yuan J, et al. Factors associated with prolonged viral RNA shedding in patients with coronavirus disease 2019 (COVID-19). Clin Infect Dis. 2020;71(15):799-806.

64. Yang SS, Lipes J. Corticosteroids for critically ill COVID-19 patients with cytokine release syndrome: a limited case series. Can J Anaesth. 2020;67(10):1462-4.

65. Zha L, Li S, Pan L, et al. Corticosteroid treatment of patients with coronavirus disease 2019 (COVID-19). Med J Aust. 2020;212(9):416-20.

66. Feng Y, Ling Y, Bai T, et al. COVID-19 with different severities: a multicenter study of clinical features. Am J Respir Crit Care Med. 2020;201(11):1380-8.

67. Wang Z, Yang B, Li Q, et al. Clinical features of 69 cases with coronavirus disease 2019 in Wuhan. China Clin Infect Dis. 2020;71(15):769-77.

68. Callejas Rubio JL, Luna Del Castillo JD, de la Hera FJ, et al. Effectiveness of corticoid pulses in patients with cytokine storm syndrome induced by SARS-CoV-2 infection. Med Clin (Barc). 2020;155(4):159-61.

69. Wang K, Zhang Z, Yu M, et al. 15-day mortality and associated risk factors for hospitalized patients with COVID-19 in Wuhan, China: an ambispective observational cohort study. Intensive Care Med. 2020;46(7):1472-4.

70. Chen X, Zhu B, Hong W, et al. Associations of clinical characteristics and treatment regimens with the duration of viral RNA shedding in patients with COVID-19. Int J Infect Dis. 2020;98:252-60.

71. Shi D, Wu W, Wang Q, et al. Clinical characteristics and factors associated with long-term viral excretion in patients with severe acute respiratory syndrome coronavirus 2 infection: a single-Center 28-day study. J Infect Dis. 2020;222(6):910-8.

72. Chroboczek T, Lacoste M, Wackenheim C, et al. Corticosteroids in patients with COVID-19: what about the control group? Clin Infect Dis. 2020.

73. Keller MJ, Kitsis EA, Arora S, et al. Effect of systemic glucocorticoids on mortality or mechanical ventilation in patients with COVID-19. J Hosp Med. 2020;15(8):489-93.

74. Yang Z, Liu J, Zhou Y, et al. The effect of corticosteroid treatment on patients with coronavirus infection: a systematic review and meta-analysis. J Infect. 2020;81(1):e13-20. 
75. Sarkar S, Khanna P, Soni KD. Are the steroids a blanket solution for COVID19? A systematic review and meta-analysis. J Med Virol. 2020.

76. Tlayjeh $\mathrm{H}$, Mhish $\mathrm{OH}$, Enani MA, et al. Association of corticosteroids use and outcomes in COVID-19 patients: a systematic review and metaanalysis. Journal of Infection and Public Health. 2020.

77. COVID-NET. Centers for Disease Control and Prevention. Accessed at October 14, 2020 at https://gis.cdc.gov/grasp/COVIDNet/COVID19_5. html

78. European Centre for Disease Prevention and Control. Accessed at October 14, 2020 at https://qap.ecdc.europa.eu/public/extensions/COVID-19/ COVID-19.html

79. Polak SB, Van Gool IC, Cohen D, et al. A systematic review of pathological findings in COVID-19: a pathophysiological timeline and possible mechanisms of disease progression. Mod Pathol. 2020. https://doi.org/10.1038/ s41379-020-0603-3:1-11.
80. Cao J, Tu WJ, Cheng W, et al. Clinical features and short-term outcomes of 102 patients with coronavirus disease 2019 in Wuhan. China Clin Infect Dis. 2020;71(15):748-55.

81. Huang $M$, Yang $Y$, Shang $F$, et al. Clinical characteristics and predictors of disease prgression in severe patients with COVID-19 infection in jiangsu province, China: a discriptive study. Am J Med Sci. 2020;360(2):120-8.

82. Liu J, Zhang S, Wu Z, et al. Clinical outcomes of COVID-19 in Wuhan, China: a large cohort study. Ann Intensive Care. 2020;10(1):99.

\section{Publisher's Note}

Springer Nature remains neutral with regard to jurisdictional claims in published maps and institutional affiliations.
Ready to submit your research? Choose BMC and benefit from:

- fast, convenient online submission

- thorough peer review by experienced researchers in your field

- rapid publication on acceptance

- support for research data, including large and complex data types

- gold Open Access which fosters wider collaboration and increased citations

- maximum visibility for your research: over $100 \mathrm{M}$ website views per year

At BMC, research is always in progress.

Learn more biomedcentral.com/submissions 